\title{
Application of LMS Moodle for distance learning foreign languages at university
}

\author{
Oksana Kandrashkina ${ }^{1}$, and Elena Revina ${ }^{2}$ \\ ${ }^{1}$ Samara State Technical University, Molodogvardeyskaya Str., 244, Samara, Russia, petergrifon@mail.ru \\ ${ }^{2}$ Samara State Technical University, Molodogvardeyskaya Str., 244, Samara, Russia, rev.e.v@mail.ru
}

\begin{abstract}
The article deals with the application of the Moodle system for teaching the subject of foreign languages (English language) at the distance learning department of Petroleum engineering at Samara State Technical University (Russia). The paper provides an outline of the course structure, tools for practical classes, independent work and the forms of assessment procedure. The course content is presented and divided into modules in a logical way according to the main education programme. The tool chosen for instruction for practical classes has been the Page tool. Tasks for independent work are provided via the Assignment tool. The efficiency of the course has been analyzed according to the data provided by the system: students' online activity in the course, fulfilled assignments and assessment reports based on the quiz results. The research has proved that the tools chosen for the course to be relevant to the subject. Analysis has shown that the learning materials and files with exercises are easily accessible. Moodle system has been considered to be appropriate for distance learning of students with a low level of language proficiency.
\end{abstract}

\section{Introduction}

The technologies for distance learning have been gaining more importance now than ever before. The wide use of personal computers and access to the internet has changed the attitude to studying and learning. Besides, the internet has undoubtedly become one of the major sources of information. It can provide a student-centered learning environment if the materials and methods are designed to take advantage of the interactivity and resources the Internet provides [1].

The quick development of information technologies nowadays has also added to the increase in various forms and tools for learning, e.g. online courses, video conferencing, etc.

It is getting more and more difficult to deal with information pressure being online, so the main task for students as well as for teachers is to orientate themselves in the great amounts of information that quickly becomes outdated and irrelevant and is constantly updating. Students must learn how to search for and analyze the necessary sources of information. These skills are important for future specialists and their professional development.

\subsection{The outline of Moodle as a distant learning system}

The key elements of any distant learning technology are interactive online courses on different websites or hubs that providing support for the educational process and assessment techniques.

There are a lot of distant learning systems, e.g. Claroline, ATutor, Ilias, Open ACS and others. Moodle (Modular Object-Oriented Dynamic Learning Environment) is considered to be the most popular and relevant e-learning platform according to recent research [2]. It has an organized interface for virtual learning and allows teachers to create online courses that students can access as a virtual classroom. It is open and free of charge platform that can be downloaded from the official website.

Educational software environment was initially oriented for teachers who did not have any special computer skills in administration of databases, websites, etc. The system is easy to use due to the accessible and clear interface. Educational management system allows designing, creating and hereafter controlling and monitoring the resources of the educational environment.

One of the advantages of Moodle is a great number of libraries and functions in PHP programming language that makes it a convenient tool for developing various information internet systems.

Another important feature is the powerful monitoring system that allows the administrator or teacher to monitor participation of students in the course and their progress. It also provides detailed information about any course module, unit and element. So students' online activity and participation in the course can be analyzed [3], e.g. how many tasks have been done by a student 
and how often he or she has accessed the course or was online.

In comparison with other distant learning systems Moodle is based on principles proposed by such scientists as John Dewey, Jean William Fritz Piaget, Ernst von Glasersfeld. The developer of Moodle Martin Dougiamas defined five principles of the learning system and united them under the name of "social constructivism" [4].

While most virtual learning systems are instructororiented and largely concerned with how course content is delivered, Moodle is based on a learner-oriented philosophy, in which students are involved in constructing their own knowledge" [5].

Nowadays the largest universities worldwide as well as Russian educational establishments make use of the Moodle system.

\section{Problem Statement}

Distance education presupposes the application of the information technologies aiming at lessening distance between a student and an instructor physically and psychologically, and to increase interactivity and interaction among students, learning sources and facilitators [6]. It also suggests using multimedia resources as well as the Internet open access resources relevant to the course of study. Distance learning technologies have become one of the common ways of learning. The first reason for it is the Internet and information and communication technologies that influence every sphere of life. The other reason is a global pandemic situation which has imposed strict regulations on the face to face interaction. Distance learning technologies for language learning have been examined by Russian and foreign scholars, especially in the UK [7]. Russian teachers focus mainly on different multimedia technologies and virtual learning systems as ways to get students more motivated and interested and publish various articles about the implementation of them in the learning process [8], and papers dedicated to advantages and disadvantages of using LMS Moodle [9].

\section{Research Questions}

It is suggested that quite simple tools and activities developed for the online course in Moodle can provide an effective learning process for students of the distance learning department. It is expected that Moodle system is easy to use so students will not face any difficulties accessing and navigating the course content and assignments provided.

\section{Purpose of the Study}

The main aim of the research is to analyse the efficiency of the Moodle system for teaching a foreign language to students from the distance department of Petroleum engineering. It examines the relevance of the tools chosen for the course content.

\section{Research Methods}

A content analysis was applied. The data provided by the system serves as a basis for the study. It includes reports that reflect participation of students in the course (time spent online in the system), total number of fulfilled assignments uploaded and assessment reports on tests taken during the term. The use of the Moodle was analysed through the frequency of access, the purpose of the accesses and the formats of the information accessed, posted or uploaded.

\section{Findings}

\subsection{Outline of distant form of learning in Samara State Technical University}

Higher education is changing very rapidly and trying to meet the needs of the very diverse stakeholders including instructors, learners and administration staff [10]. Russian higher educational institutions being aware of the global educational changes have also modified the forms of learning according to the needs of the students. Russian universities have begun using virtual learning systems primarily for distance learning and blended learning.

Samara State Technical University (SSTU) has been applying online systems for distance learning because of the increasing demand for computerization of educational process. The technological platform chosen for distance learning has been the Moodle system. Application of LMS Moodle forms the informationeducation environment that compensates for lack of personal communication between a teacher and a student in distance learning and supplements full-time form of education with the technologies used in online courses development [10].

At first Moodle was used primarily for the distance learning department. Distance learning is not considered to be an innovative way of studying as it has existed for decades. Several years ago, learning at the distance department was carried out in the form of short-term face to face sessions including lectures and seminars. Students had to study for 5 or 6 years. It was obligatory for students to attend classes one or two weeks during the semester and to get credits and take exams at the end of the term at the university. The educational process was conducted without any application of information technologies or e-learning systems. It presented some problems for students who lived in other cities or worked in shifts and had to travel the long way to the university to attend classes and take exams.

Since then the form of learning has changed completely. Traditional form of learning has been replaced by distance learning that is organized with the application of the Moodle system. The education process can be characterized as blended because some subjects in the curriculum require students' attendance. As far as the foreign languages are concerned, the education process is carried out via LMS Moodle. 
To work in LMS effectively, the university provides training courses for teaching staff where everyone can try and create his/her own online course. Different subjects require the use of different Moodle tools, e.g. lectures must be accompanied by video recordings or presentations.

It should be noted that teachers having basic computer skills and Internet skills connected have no difficulties in learning how to work in the Moodle system. Only with the help of a reference system a teacher is able to create an online course in any discipline that will include:

- information activity-oriented content (forum, wikiprojects, online meetings, lectures, quizzes, multimedia resources, additional materials);

- assessment content (the analysis of the test/quizzes results in every group, a report of students' activity during the course);

- administrative content (user registration, role confirmation, assigning roles) [11].

\subsection{Course Structure}

Most students entering the department have elementary or beginner level of English. It is explained by the fact that there are mostly adult students who finished schools or colleges many years ago and have not had any foreign language experience since then. It specifies the choice of teaching methods and the content of the course. The course has been developed according to the main educational programme on the subject of the foreign language, approved by the Federal Educational Standard of the Russian Federation and Samara State Technical University.

The course structure is important and must correspond with the education program. All language courses must include materials for so-called "practical studies" and individual training activities, so the course structure must be clear and well-organized. Moodle provides the tools needed to design and implement appropriate language learning courses that use online activities. Within Moodle three types of tools are distinguished: for structuring and design; for content and activities; for collaborative learning. Each tool contains a variety of modules that can also be connected to other platforms.

As for the subject of foreign language itself, there are some components essential for the quality of language learning programmes:

- general didactic (individualization of instruction, active role of a student)

- linguistic (language accuracy and language norm)

- methodical (communicative and professional relevance of content)

- digital (interactive forms of learning, module content structure, multimedia and online resources) [12].

The above-mentioned aspects should be taken into consideration for online course development.

At the distance department of Petroleum engineering of SSTU the subject of Foreign Language is taught in the $3^{\text {rd }}$ and $4^{\text {th }}$ terms. Each term has academic hours for practical classes, for independent work and for assessment procedure. Practical classes take up from 8 to 4 hours depending on the semester. Independent work accounts for a very substantial amount of time - 124 hours each term. Assessment form depends on the semester; students get credit after the $3^{\text {rd }}$ term in the form of a test and take an exam in the end of the $4^{\text {th }}$ term. The education programme is divided into the following modules: Personal Profile, Education, My Specialty and Engineering, Professional Background and Skills. Each term covers two modules from the programme.

Course content in Moodle is also divided into modules according to the education programme. Each module consists of several sections where learning material is presented according to the syllabus. It includes instruction materials for practical classes, tasks and exercises for independent work and quizzes in the form of tests. Each course element has a short description for students. Taking into consideration the low level of language proficiency of the students the descriptions for the course elements and grammar explanations are written in the native language.

Each activity or tool within one module has a date and time restriction. Each of the following pages or assignments can be seen and studied according to the date and time set by the teacher. So course materials can be reached over the internet and can be saved and looked through later. All lesson related activities are shown in the weekly format and a student can easily see and follow all activities that will take place in a semester [2]. So in general a student has one particular activity or task every week in such a way that practical studies are followed by assignments for practicing new skills and abilities [13]. In the foreign language course a new activity is accessible every other Monday. In such a way of organizing a course a student does not have access to the whole course content from the beginning of the term.

\subsection{Practical studies}

Course content for practical classes provides students only with the basic educational material. Students first must get familiar with the material and then apply the knowledge of new material in order to do exercises for individual work (e.g. practice grammar skills, exercises on new vocabulary or reading comprehension).

Practical classes are created in the form of a Page tool in Moodle. A Text page is a simple page created in the form of a plain text and looks like a page of a Word document. Text pages are simple, but they are appropriate for delivering information or instructions. Page tool is convenient for practical classes as the information is displayed right on the screen in the system and students do not need to download any files. Different media like pictures or graphics can also be added on the page.

Each page has a short description of the material provided. The description is written in the native language due to the elementary level of language of the students. 
Practical classes include such language aspects as grammar, vocabulary and reading. The course content is designed in such a way the practical studies alternates with independent tasks and tests. First there is a practical class available for studying and then tasks for practicing new language material presented earlier.

Grammar is represented by grammar rule explanation and examples. The example of the grammar section is shown in Fig. 1. It is a part of a grammar rule - a table with different forms of pronouns.

The Vocabulary section has a page with a list of words and phrases connected with the studied material. New lexical terms are given with the translation. Students have to read and learn the words that later will be used and practiced in different exercises.

The Reading section usually consists of a simple text and tasks for general understanding and understanding of the main idea. The tasks are of the following types: matching, True/False statements, questions and gapfilling exercises.

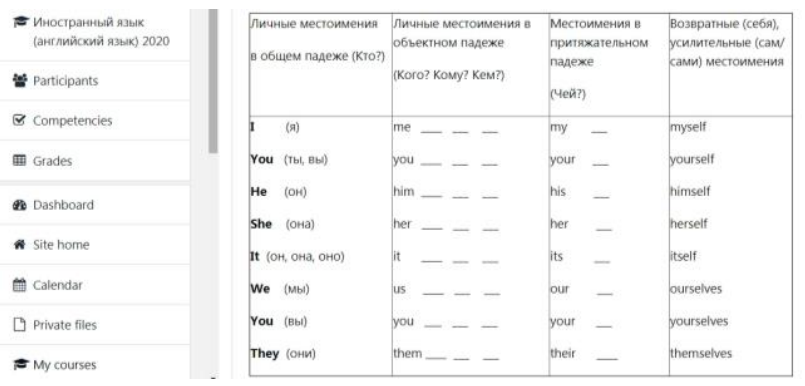

Fig. 1. The Page representing a grammar rule

The analysis of students' frequency of access to these sections has shown that no one has had any difficulty in getting familiar with new material from the technical point of view. All students managed to access the content in time after it has become open for them in the system. We can conclude that the Page tool allows presenting the instruction material in a simple and appropriate way.

\subsection{Independent work}

Any distance learning technologies involve a great amount of independent work that students have to do. So various types of assignments form the most course content. Besides, there are links to open access Internet resources to facilitate the understanding of new material, especially connected with grammar points. The online course includes mainly independent work of the reproductive type and cognitive-search-type.

The tasks in our course have been created with an Assignment tool. Each assignment is provided with a file that a student has to download and do exercises in it. As soon as fulfilled tasks have been submitted and uploaded, a teacher can see how many students have done the task and then check it.

The types of exercises in the Assignment sections for practicing various language aspects are the following:

Exercises for practicing grammar:

fill in the gaps with the correct forms/words given; match questions with responses;

put words into correct order to make a sentence rule

change the form of a word according to the grammar

Exercises for practicing vocabulary:

match words and phrases and their translation;

fill in the gaps with words.

Exercises for reading comp:

answer the questions to the text;

define True/False statements ;

choose the correct answer.

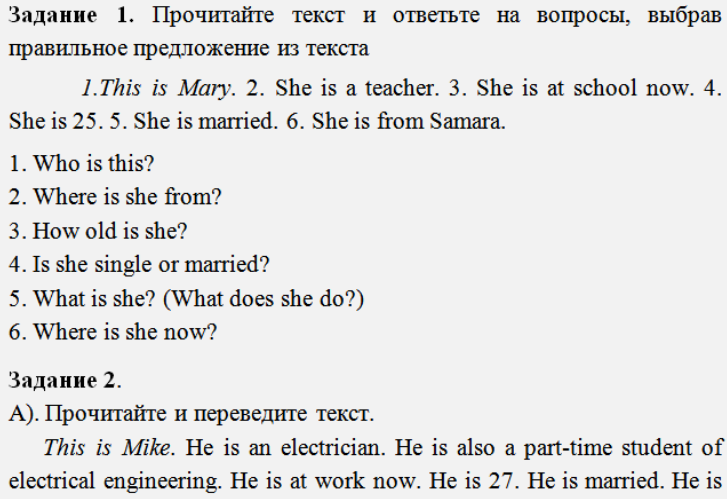

Fig.2. Example of the exercise to practice reading comprehension

Fig. 2 shows an elementary reading comprehension task - answering the questions to the text that presupposes matching questions and answers. It is a very simple exercise created with the Assignment tool and uploaded in the course in the form of word-office document. The Assignment tool is used in the course to upload the files with the tasks that students must first download, then complete and then upload as a submission to the assignment. The teacher then check the files. The assignments are taken into consideration and give additional grades to a student at the end of the term.

Having analyzed students' files with accomplished tasks, it should be noted that this kind of the form of organizing independent work appeared to be relevant and easily accessible for students.

\subsection{Assessment}

One of the most difficult methodical problems of distance learning is the assessment. In order to choose an assessment form it is necessary to match the chosen form of assessment with the education content and with the teaching techniques. If one needs to check the understanding of facts (what is to be done), the knowledge of processes (how it is to be done) or strategic vision (why it should be done in such a way), then a quiz seems to be the best option. Quizzes in the forms of tests allow getting the results quickly and analyze them.

The online delivery of teaching, perhaps on mobile devices, enables smooth progression from teaching resources to assessment and back again. Questions can be asked at the most appropriate point in the teaching, 
and attempted wherever and whenever the students are doing their studying.

Even the simplest of multiple-choice quizzes can enable students to check their understanding of a wide range of topics, whenever and wherever they choose to do so [14].

In our course we make multiple-choice questions test. First we create a test in Microsoft Excel and then convert it into the Moodle quiz form that can be uploaded to the system. There are several progress short module tests for one section consisting of 8-12 questions and one final test at the end of the term.

It is convenient to save all the questions in a question bank in Moodle that is an overall stock of all the questions and tasks you have uploaded on the platform.

Each module includes 2 tests so there are 4 tests per term and one final test. The final test consists of the questions from the module tests and has additional multiple-choice questions. The scores from the module tests are taken into account for the final grade (credit or exam).

All the questions are uploaded and saved in the Question bank, so the teacher can change and modify the test if required and choose questions relevant to the particular module or language skill.

There is a time limit set to each attempt and restricted access (by date) to every test. Moreover the number of attempts is also limited to 3 times. All the quiz settings allow obtaining credible results and decreasing the level of cheating.

Quiz reports show the time of the beginning and completing a test, overall grade and correct/incorrect answers to the questions. This powerful monitoring system helps the teacher to understand what part of the course content has not been acquired on full scale and what topics are more difficult to study for some students.

Assessment reports are valuable and convenient because a teacher doesn't have to follow every student separately - you can easily get the grades of a whole group from the report provided by the Moodle system. As it is shown in Figure 3, the most difficult questions of the test can be identified and then the weak points might be revised or studied again, or the teacher can replace more difficult questions with the easier ones.

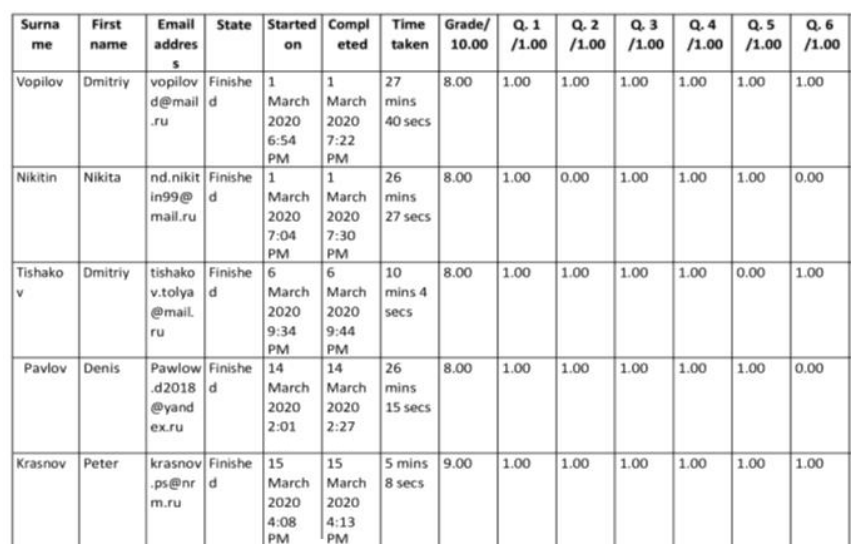

Fig.3. Quiz report with a question number (Q.) answered or failed
We have analysed several data provided by the Moodle system concerning students' learning and completion of one semester. Table 1 provides the data from the system.

Table 1. Data provided by the Moodle system

\begin{tabular}{|c|c|c|c|}
\hline $\begin{array}{l}\text { Total } \\
\text { number } \\
\text { of } \\
\text { students } \\
\text { enrolled }\end{array}$ & $\begin{array}{l}\text { Students } \\
\text { completed } \\
\text { the } \\
\text { assignments }\end{array}$ & $\begin{array}{c}\text { Studen } \\
\text { ts } \\
\text { passed } \\
\text { final tests }\end{array}$ & $\begin{array}{r}\text { Student } \\
\text { not } \\
\text { accessing } \\
\text { the course }\end{array}$ \\
\hline 180 & 170 & 167 & 2 \\
\hline $100 \%$ & $94,4 \%$ & $92,7 \%$ & $1,1 \%$ \\
\hline
\end{tabular}

Table 1 shows that about $94 \%$ of students have completed the course in the $3^{\text {rd }}$ term within the term 's deadlines. About $7 \%$ of students fulfilled the tasks and took tests after the term's deadline. The percentage of students who passed the final test proves the statement that the Moodle system is easily accessed and has a clear interface.

\section{Conclusion}

The paper analyzed the efficiency of the online course in the Moodle system for teaching the foreign language at the distance learning department. The online course content structure and Moodle tools chosen for the course have been examined. To conclude, the online course has proved to be effective due to the simple and clear structure and a user-friendly interface. The study has shown that the students didn't face any difficulties accessing the course content and navigating it. Moreover, the applied Moodle tools turned out to be quite effective in delivering the course content for students with a low language level. Thus, the Page tool in LMS is considered to be an appropriate way of providing new learning material for students [15]. The Assignment tool is convenient for our course because the task or exercise comes in a form of a file that is uploaded to the system and course participants need to download it. Assessment procedure is performed via multiplechoice tests that considerably facilitate evaluation of students by automatic grading. The research has shown that such simple tools and clear course structure make it possible to deliver the learning material and improve language skills of students with a low level of language proficiency.

\section{References}

1. M. Simonson, S. Smaldino, S. Zvacek, Teaching and learning at a distance (IAP-Information Age Publishing, Inc, 2015)

2. N. Cavus, Procedia - Social and Behavioral Sciences 191 872-877 https://doi.org/10.1016/j.sbspro.2015.04.611 
3. T. Markova, I. Glazkova, E. Zaborova, Procedia Social and Behavioral Sciences 237, 685-691 (2017) https://doi.org/10.1016/j.sbspro.2017.02.043

4. M. Dougiamas, A journey into constructivism, (1999),

URL: https://www.researchgate.net/publication/20002240 4 A journey into constructivism (date of access: 10.12.2020)

5. A. Chavan, S. Pavri, Open-source learning management with moodle. Linux Journal 12, 66-7 (2004)

6. R. D. Costa, G. F. Souza, R. Valentim, B. Castro, Cognitive Systems Research 64, 134-145 (2020) https://doi.org/10.1016/j.cogsys.2020.08.00

7. B. Holmberg, M. Shelley, C. White, Distance Education and Languages: Evolution and Change (Multilingual Matters Ltd, Bristol, 2005)

8. I. Rymanova, N. Baryshnikov, A. Grishaeva, Procedia - Social and Behavioral Sciences 206, 236240

https://doi.org/10.1016/j.sbspro.2015.10.01

9. S. Tsvetkova, I. Malinina, (2019). Engineering education, 25, URL: http://www.acraee.ru/files/io/m25/art_8.pdf (date of access: 10.12.2020)

10. D. Keržič, A. Aleksander, N. Tomaževič, L. Umek, International Journal of Innovation and Learning 21 $\begin{array}{llll}\text { (2), } & 165-177 & \text { (2017) }\end{array}$ 10.1504/IJIL.2017.10002132

11. N. V. Khudoley, RUDN Journal of Informatization in Education 15 (4), 410-32 (2018)

12. A.N. Bekhterev, A.V. Loginova, Open Education 4 (99), 91-97 (2013) https://doi.org/10.21686/18184243-2013-4(99)-91-97

13. C. Costa, H. Alvelos, L. Teixeira, Procedia Technology 5, 334-343, (2012) https://doi.org/10.1016/j.protcy.2012.09.03

14. K. Lee, H. Choi, Y. H. Choy, The Internet and Higher Education 41, 25-33 (2019) https://doi.org/10.1016/j.iheduc.2018.12.001

15. D. Yawson, F. Yamoah, Heliyon 6 (11), 1-9 (2020) https://doi.org/10.1016/j.heliyon.2020.e05519 